\title{
IMPACTOS RELACIONADOS À IMPLANTAÇÃO DE ERP: UM ESTUDO DE CASOS COMPARADOS
}

\section{IMPACTS RELATED TO THE ERP IMPLEMENTATION: A STUDY OF COMPARATIVE CASES}

\author{
Luiz Augusto Machado Mendes Filho' ${ }^{1}$ Cristiane de Araújo Teixeira ${ }^{2}$ \\ ${ }^{1}$ Faculdade Natalense para o Desenvolvimento do RN - FARN - Rio Grande do Norte - Brasil \\ luiz@,farn.br \\ ${ }^{2}$ Faculdade Natalense para o Desenvolvimento do RN - FARN - Rio Grande do Norte - Brasil \\ cristiane@,farn.br
}

Recebido para publicação em: 01/03/05 Aceito para publicação em: 10/10/05

\begin{abstract}
Resumo
A filosofia de um Sistema Integrado de Gestão (ERP) acarreta em mudanças culturais $e$ comportamentais de alto risco, sendo seu custo e complexidade igualmente altos. Dai a importância de analisar e ponderar sobre a relação custo $x$ benefícios. Diante deste fato, este trabalho é o resultado de um estudo de múltiplos casos realizados na TELEMAR/Natal e na COSERN, baseando-se nas informações referentes aos impactos relativos à implantação do Sistema ERP. Foi realizada uma pesquisa descritiva-exploratória, através de questionários com os gerentes dessas empresas, procurando descrever a utilização do Sistema ERP, explorando os temas inerentes a um projeto de tão alto custo e complexidade. Conclui-se que o ideal é que as empresas devem elaborar o plano estratégico de forma que este seja o ponto de partida rumo aos objetivos traçados, adaptando seus sistemas e fazendo uso de metodologias que contemplem, não somente a obtenção do lucro com custos reduzidos, como também o desenvolvimento intelectual dos recursos humanos.
\end{abstract}

Palavras-chave: Sistemas integrados de gestão; ERP; impactos.

\section{Introdução}

A atual sociedade da informação exige que as empresas, como seu principal agente de mudanças, façam uso da TI (Tecnologia de Informação) para suportar o grande fluxo de dados, tomada de decisões rápida e constante adaptação às mudanças. Para isto o ERP (Sistemas Integrados de Gestão) é visto como a solução tecnológica que propiciará integração e facilidade na percepção de como planejar e administrar os recursos, através de atualizações, incluindo cada vez mais práticas novas de gestão a partir da experiência acumulativa dos fornecedores destes pacotes de software.

De acordo com Kalakota e Robinson (2002), sem a implementação de ERP é quase impossível atingir a integração de todos os processos, pois estes pacotes de software, desenvolvidos em módulos, são tidos como a coluna-mestra tecnológica da empresa, aplicando-se à geração do conhecimento necessário para auxiliar na tomada de decisões, juntamente com outras tecnologias, tais como: Data Warehouse (DW), Data Mining (DM), Executive Information System (EIS), 
Internet e os recursos On-line Analytic Processing (OLAP) e On-line Transaction Processing (OLTP).

Entretanto, como bem definiram Toraldo, Saporeti e Zanquetto Filho (2001), todo projeto de implantação de um sistema integrado ERP requer, primeiramente, o rompimento dos preceitos e das formas de trabalho mantidos desde a era industrial.

Portanto, este trabalho tem como objetivo descrever os impactos provenientes da implantação de Sistemas ERP em duas empresas prestadoras de serviço na cidade de Natal/RN (TELEMAR e COSERN), levando-se em conta os seguintes aspectos: antes da implantação do ERP, impactos iniciais, estratégia empresarial, investimento e cultura organizacional

\section{Impactos de ERP's nas empresas}

O ERP propicia a evolução do ambiente computacional, uma vez que desloca o poder de um setor específico de processamento de dados (CPD) para os próprios usuários. Usando isto como item motivador, estes terão maior responsabilidade, mas em contrapartida, mais interatividade e reconhecimento em seus atos.

As mudanças no contexto empresarial - concorrência acirrada, necessidade de decisões rápidas e econômicas, mundo globalizado e pressão dos usuários por mais qualidade - fortaleceram o uso de Sistemas ERP no mercado (REZENDE; ABREU, 2001).

Para Menezes (2003), o ERP tem como proposta a integração, de maneira dinâmica e eletrônica, de todos os processos operacionais da empresa, evitando assim, qualquer tipo de reentrada de dados. As informações geradas por todos os módulos do software alimentam uma mesma base de dados, auxiliando efetivamente na tomada de decisões.

Segundo Wood Jr. e Caldas (2000), na análise da adoção do ERP deve-se estar atento à ocorrência dos fatores substantivos, institucionais e políticos. Os primeiros referem-se aos imperativos reais que resultam na necessidade para a aquisição do ERP; o segundo fator diz respeito às forças externas atuando sobre e na organização, é o caso da imposição de fornecedores de software e/ou empresas de consultoria; e por fim, o fator político é aquele que reflete o interesse dos grupos de poder dentro da empresa.

De acordo com Souza e Zwicker (2000), o ciclo de vida do sistema ERP passa pela etapa de decisão e seleção, onde a consideração acerca das vantagens e desvantagens, a escolha do fornecedor do software e o planejamento de como implementá-lo são os pontos relevantes.

A etapa de implementação refere-se ao processo pelo qual os módulos do sistema são colocados em funcionamento, envolvendo as parametrizações e customizações necessárias para que haja uma devida adaptação. É a etapa em que, feito um levantamento acerca dos dados imprescindíveis para todo o suporte ao fluxo de informações, estes serão migrados dos antigos sistemas ao ERP. Esta etapa abrange ainda a reengenharia e mudanças na infra-estrutura tecnológica no tocante aos equipamentos, servidores e redes, com o devido treinamento dos usuários que irão, a partir desta etapa, usar o software.

Após o processo de implementação, a etapa de utilização passa a nortear as operações diárias. Esta etapa é muito importante no sentido de passar a conhecer, de fato, todas as possibilidades que incorrerão em novas necessidades, chegando ao ponto de implementar novos módulos ou, em último caso, avaliar novamente os procedimentos operacionais para que estes possam adaptar-se às novas exigências.

Conforme Buckhout, Frey e Nemec Jr. (1999), o software ERP integra as diferentes funções da empresa para criar operações mais eficientes. No entanto, sua implementação é considerada problemática. São duas as principais razões por tal dificuldade na implantação destes sistemas:

- Algumas empresas não fazem as escolhas estratégicas necessárias para adaptar o software à empresa ou o contrário. Tampouco redesenham todos os processos operacionais, ficando praticamente impossível modificar o sistema após a constatação do erro.

- O processo de implementação pode escapar ao controle porque, muitas das vezes, os diretores encaram a implantação destes sistemas somente sob o ponto de vista de um projeto de tecnologia e 
não como um projeto empresarial. Com isso, ao se perder de vista os objetivos empresariais que resultaram na necessidade de se adquirir tais sistemas, muitos diretores começam a apressar a implantação, correndo o risco de super ou subvalorizar certas funções operacionais.

De acordo com Souza e Zwicker (2000), mesmo estando amparado por transformações tecnológicas - arquitetura cliente/servidor, processamento distribuído, servidores especializados, tecnologia de rede, programação orientada a objetos e ferramentas CASE - que consolidaram seu espaço nas gestões modernas, a filosofia do software ERP acarreta em mudanças culturais e comportamentais de alto risco, sendo seu custo e complexidade igualmente altos. Daí a importância de analisar e ponderar sobre a relação custo $\mathrm{x}$ benefícios.

Uma outra desvantagem pode acontecer se as empresas contratantes dependerem de um único fornecedor e a decisão da melhor prática ficar nas mãos da empresa contratada e não do comprador e, uma vez que o ERP aprisiona os princípios e processos, segundo estas melhores práticas de gestão, constatado tardiamente algum erro, fica praticamente impossível modificá-lo após total implementação do sistema (RAMOS; MIRANDA, 2003).

O conhecimento e análise da melhor abordagem para a empresa, associado ao uso de metodologias, reduzem o risco de impactos negativos e trazem consistência ao sistema como um todo. Ao mesmo tempo, o desenvolvimento constante para novas habilidades e situações exige dos líderes um cuidado maior no gerenciamento desta transformação.

\section{Metodologia da pesquisa}

A pesquisa realizada foi de natureza descritiva-exploratória e teve por objetivo aprofundar o entendimento dos impactos antes e durante à implantação e utilização de sistemas ERP. Para tanto foram analisados os casos de duas empresas de grande porte que implementaram sistemas ERP. A escolha de realizar um estudo de múltiplos casos se justifica pelo fato de que fica mais generalizada as observações constatadas, em contrapartida do estudo baseado num caso único em que a empresa escolhida deve ser um exemplo crítico de teoria bem formulada, o caso deve ser extremo e único, além de possuir características reveladoras para a pesquisa (YIN, 1994).

As fontes de coletas de dados utilizadas foram entrevistas estruturadas, através de um roteiro previamente enviado, contendo doze perguntas abertas, acompanhadas de observação direta intensiva. Em cada uma das empresas foram entrevistados dois gerentes e as entrevistas foram realizadas entre outubro e novembro de 2003.

As empresas selecionadas para o estudo foram:

- COSERN: a Companhia Energética do Rio Grande do Norte é responsável pelo fornecimento de energia elétrica para $100 \%$ do território do Estado do RN, atendendo a mais 770.000 clientes;

- TELEMAR: a organização é hoje a maior empresa de telecomunicações do Brasil em faturamento e em número de telefones instalados. Com larga experiência em serviços de telefonia fixa local e de longa distância, disponibiliza-se também serviços para Internet, Transmissão de Dados e Imagens e Videoconferência, entre outros.

\section{Análise de resultados}

Para descrever os impactos provenientes da implantação de Sistemas ERP na TELEMAR e COSERN, este capítulo ficou dividido em cinco tópicos: antes da implantação do ERP, impactos iniciais, estratégia empresarial, investimento e cultura organizacional.

\subsection{Antes da implantação do ERP}

Vários eram os sistemas operantes na TELEMAR, específicos para cada setor da empresa de telecomunicações local. Estes sistemas legados, devido às muitas aplicações isoladas, ocasionavam 
uma comunicação entre estes setores através de uma série de interfaces, complexas e caras de manter a cada mudança de regulamentação ou mesmo de procedimentos.

A falta de padronização, em termos de estrutura dos dados, era uma constante entre as Sedes Regionais, e entre estas e a Central, incorrendo em demora e re-trabalho para que a avaliação, na sua totalidade, fosse efetivamente posta em estudo pela administração geral da TELEMAR no Rio de Janeiro.

Quanto à conscientização prévia para com os usuários, foi identificado que a sede nacional no Rio de Janeiro tomou a decisão sem a participação de gestores das áreas regionais, o que inviabilizou a condução do projeto local de forma harmônica e participativa. Os funcionários foram avisados da decisão, de forma imposta simplesmente, e receberam um treinamento de três meses na sede regional, em Recife, e após este, somente os mais capacitados ficaram para coordenar as atividades que ficaram como resultado da reengenharia aplicada anteriormente.

A consultoria contratada para a elaboração e execução da implantação na TELEMAR foi a Price Waterhouse, que começou a desenvolvê-lo na sede aqui em Natal em agosto de 1999, tendo concluído a implantação em maio de 2000. Não tendo sido designado nenhum integrante chave dos setores da empresa ficou a realização por idéia e experiência da própria consultoria.

Sem a participação no destino da empresa, os diretores locais acolheram a decisão e só estiveram a par dos testes, que foram feitos em paralelo, e da própria migração final dos dados. As configurações necessárias à adequação do sistema à empresa não fizeram parte do repertório de ações previsto para a direção local e seus demais componentes. Ao mesmo tempo, a implementação rápida do sistema não possibilitou a medição da satisfação do usuário em cada uma das fases seguidas pela metodologia, assim como estava determinado.

A condição anterior do ERP na COSERN constava de muitas falhas - erros e redundâncias nos dados - fruto de múltiplos e descentralizados sistemas. Muitas subestações ainda não eram automatizadas, ocasionando em um serviço falho dentro dos critérios exigidos. Um modelo de otimização para testes de comissionamento de subestações já tinha sido formulado, restando integrá-lo às demais partes do sistema de distribuição e assim garantir uma melhor qualidade no fornecimento de energia elétrica.

Seguindo análises feitas em todo o corpo da corporação ficou determinado que, para dinamizar todo o processo de gestão da empresa, em suas três etapas: planejamento, execução e controle, seria necessário obter informações úteis no tempo certo, e isso só seria possível se todos os subsistemas da empresa fossem interligados, trabalhando em tempo real, não mais deixando para digitar no final do mês todas as informações relativas ao período.

Conscientização e apoio da parte da nova administração da COSERN foram uma constante desde o início, tendo sido fonte de investimento, dentro do projeto como um todo, a divulgação da intenção em adquirir um sistema integrado, a comunicação dos benefícios do ERP, o quanto se precisava deste na viabilização de novos e grandiosos projetos, o treinamento da equipe de implantação e com os próprios usuários finais.

Workshops facilitaram a dinâmica da preparação para a mudança, aliada ao direcionamento pela alta administração em compartilhar a gestão nos serviços terceirizados, possibilitando adesão destes à nova realidade que estaria por vir e fazendo com que as partes envolvidas se sentissem motivadas a perseguir sempre os melhores resultados gerais.

O projeto de implantação entrou em produção na COSERN em julho de 1999, tendo sido fato de orgulho por todo o esforço alcançado na parametrização e configurações necessárias para que o sistema se adequasse à empresa.

\subsection{Impactos iniciais}

No tocante aos impactos mais aparentes na TELEMAR foi a imposição para tal mudança, de sistemas múltiplos em um sistema único, seguido do impacto comportamental, ou seja, que funções ainda seriam necessárias após o realinhamento em processos. 
A empresa Price Waterhouse começou treinando o pessoal da Central no Rio de Janeiro, estes, por sua vez, vieram às sedes regionais prestar acompanhamento e seleção dos mais capacitados. Depois do treinamento para os 880 funcionários da TELEMAR/Natal, à época da transição, foi constatado que os que operavam os sistemas antigos tiveram mais dificuldade em interagir com o ERP, sobretudo porque houve uma pressão pela rápida absorção dos detalhes técnicos para com o novo sistema, e aqueles que não faziam uso de tais sistemas anteriores não tiveram muitos problemas, ao contrário, até se empolgaram na utilização do ERP.

O impacto positivo inicial na COSERN teve um teor econômico, estimava-se uma redução anual de gastos na ordem de $\mathrm{R}$ \$ 14,7 milhões. Além deste, a redução no tempo da contabilização da folha de pagamento, no tempo do fechamento contábil do mês, informações gerenciais mais úteis contribuindo para uma ação mais rápida e eficaz, o intercâmbio de dados e processos que eliminou a redundância de dados e o retrabalho da digitação foram logo sentidos.

Com a entrada do sistema foram identificados também, ainda que em caráter quantitativo os seguintes benefícios: melhor gerenciamento de estoque, planejamento de compras, controle e execução de obras, distribuição de pessoal e gerenciamento de prestadoras de serviços.

Em caráter qualitativo tem-se ainda, o controle de acesso ao sistema, o acompanhamento online, transações em tempo real, integração de dados, trilhas de auditoria, padronização de procedimentos, melhor nível da informação, upgrade continuado e visão por processos.

Em termos não muito positivos evidenciou-se que o sistema não poderia atender totalmente às funcionalidades da COSERN. É o caso da área de Segurança e Medicina do Trabalho, que atualmente está em vias de negociação para que o mesmo seja contemplado com um software específico, que venha a atender as necessidades do setor, mas que de preferência seja homologado ou parceiro da empresa escolhida.

\subsection{Estratégia empresarial}

A conclusão a que se chegou para o caso da TELEMAR neste tópico foi a de que, tendo em vista a adoção do sistema ERP ter sido realizada pela Price Waterhouse (empresa de Consultoria), pode-se concluir que o fator institucional foi mais relevante que o fator político, o que ocorreu em uma inadequação entre os objetivos estratégicos e a imposição, às vezes cercada por modismos, que se abateu sobre a empresa.

A questão do impacto, sobre a situação a médio e longo prazo nesta empresa, poderá vir a denotar uma perda de senso crítico da mesma para com a condução posterior à implementação, ou melhor, na sua utilização, pois a mesma, sem ter apreciado a aquisição do software a partir do seu próprio ponto de vista perdeu a oportunidade de evoluir, tanto em termos tecnológicos, como em termos de amadurecer a sua equipe administrativa, que não caiu em campo para avaliar melhor as possibilidades, como também não permitiu maior integração humana renegando sua condição criativa a de mero executador.

$\mathrm{O}$ estudo da viabilidade econômica foi documentado, quer dizer, a relação custo $\mathrm{x}$ benefícios foi analisada mediante a possibilidade do ERP melhorar os processos da empresa, reduzir os custos e melhorar a rapidez e a qualidade do serviço final. Pelo menos neste aspecto a empresa se preocupou em acompanhar, por escrito, a estratégia definida pela Consultoria a ela prestada, portanto, o planejamento estratégico teve uma conotação positiva para a condução do projeto, apesar de ter subestimado a satisfação dos usuários, preservando o direcionamento por escrito para uma adequada avaliação futura e de forma a comparar o que foi idealizado e realizado.

No caso da COSERN, segundo os dados coletados pelos entrevistados desta empresa, teve como síntese a formulação de uma definição, pelos próprios usuários do sistema ERP, como sendo um sistema de software, com flexibilidade, integração, facilidade de implantação e exatidão nos cálculos, que foi desenvolvido com uma tecnologia de vanguarda. É de se concluir que, a mesma antecipou as mudanças em seus impactos mais relevantes, o econômico e o comportamental, em paralelo às negociações internas quanto ao melhor fornecedor deste tipo de software de gestão, ressaltando que outras alternativas também foram levadas em consideração. 
A estratégia da COSERN, frente aos seus pontos fortes e à sua necessidade de integração, contemplou as mais diversas possibilidades até chegar à adoção do ERP, no entanto, ficou preservado, de forma igualmente estratégica, o setor de vendas e distribuição, por ser esta a função básica da empresa e pelo próprio Grupo IBERDROLA deter o conhecimento das melhores práticas utilizadas neste segmento.

Os fatores mais relevantes nesta decisão têm a ver com os fatores substantivos - a necessidade de integração - e políticos - a segurança e independência dos administradores da empresa na solução dos problemas que se reportavam à desintegração da mesma.

\subsection{Investimento}

Como o ERP representou um investimento estratégico, o risco era muito alto. Entretanto, a TELEMAR estava disposta a arcar como o ônus. Mesmo não tendo sido revelado o valor para tal modernização na empresa, sabe-se que o peso, ante uma frustração, seria passível de uma desestruturação na organização. A metodologia usada para desenvolver o projeto abordou os passos a serem seguidos e as equipes responsáveis por cada atividade tiveram que implementar o sistema dentro do prazo estipulado, para não incorrer em um custo maior.

Quanto a este tópico conclui-se que, o impacto econômico estava longe de ser sentido pelos funcionários em etapa anterior à implementação, mesmo assim, os que validaram a decisão estavam autorizando o projeto de forma não tão segura, principalmente por não conhecer, na sua totalidade, como outros casos haviam sido conduzidos, pois as informações advinham da empresa de consultoria.

Na outra empresa, o projeto de implantação do sistema teve início em janeiro de 1998, com a contratação da empresa de consultoria Ernst \& Young que, em parceria com os técnicos da COSERN, realizou as configurações e parametrizações necessárias ao sistema. Foi investido um total de R\$ 13 milhões, desde a compra de licenças de utilização do sistema, passando pela aquisição de equipamentos e treinamento, até as manutenções realizadas no sistema e a própria contratação da consultoria.

O impacto econômico quanto ao custo, só foi sentido de forma consciente e positiva porque a empresa estava no comando e porque o projeto, em todas as suas considerações, pendia para uma economia anual de mais de $\mathrm{R} \$ 14$ milhões.

\subsection{Cultura organizacional}

A empresa TELEMAR não dispunha de um programa de capacitação que predispusesse os funcionários a uma prévia preparação, nem tampouco se preocupava em disseminar a filosofia da empresa, ou mesmo seus pontos fortes e seus objetivos. A estrutura anterior ao ERP estabelecia um conglomerado de departamentos sem sinergia e sem intenção de se integrarem. O único fato que prevalecia era a competição frente à dominação de certos grupos internos no que se referia à geração de certo conhecimento específico de cada setor.

A análise deste impacto, tendo em vista a elucidação deste tema, ilustra um caso típico de organização que, por deter uma parcela do mercado muito grande e, por ter uma visão mais voltada aos custos e receitas, não possibilitava muito o desenvolvimento interpessoal tão em pauta ultimamente. $\mathrm{O}$ impacto foi sentido de forma negativa e dado a resistência, pois, a idéia subjacente à forma antiga de se trabalhar revelava certos domínios de informação e, conseqüentemente de poder, não facilitando a democratização do saber organizacional.

Para a COSERN, entretanto, a própria caracterização do sistema como uma ferramenta poderosa, mas auxiliar, no apoio às operações básicas e, principalmente como subsídio à tomada de decisões propiciou a participação, com considerável empolgação, devido à existência de uma cultura forte que sempre primou pelo aculturamento dos funcionários, desde a sua capacitação 
técnica até o seu desenvolvimento interpessoal. A questão da dominação da informação, por alguns setores, não foi mencionada, mesmo porque não fazia parte da estrutura uma hierarquia muito vertical desde antes do ERP.

Portanto, a percepção dos envolvidos em busca dos objetivos propostos se deu em um clima favorável ao treinamento e ao engajamento. Tendo na fase inicial de utilização a disseminação de que o mais importante é o recurso humano e que o significado que se dá ao manuseio da tecnologia não se compara à criação e ao despertar do indivíduo, em todo o seu potencial. Segundo um dos entrevistados, fazer certo determinada tarefa não é o mesmo que fazer a tarefa certa.

\section{Conclusão}

Na TELEMAR a visão à longo prazo não foi muito embutida neste projeto, pois o comprometimento de todos seria um fator de sucesso perante o mesmo. A forma de conduzir a mudança foi vista como a desejar pelos entrevistados, porque eles sentiram o desinteresse por parte da empresa em capacitá-los melhor para a situação emergente.

Em compensação, a mudança, no que tangia à agilidade e à facilidade para tomar as decisões que favorecessem questões operacionais e de cunho competitivo, denotaram um impacto favorável na visão dos administradores.

Aliada a uma cultura que privilegia o indivíduo, a COSERN soube fazer da horizontalização da sua estrutura, um fator a mais para a comunicação sem rodeios e com um significado de comparação entre as responsabilidades de cada setor com vistas ao resultado final. O impacto do ERP, nesta empresa, foi sentido de forma positiva, as mudanças foram comunicadas e tidas como um desafio pessoal, grupal e organizacional ao mesmo tempo.

O impacto sentido pelos líderes na tentativa de alinhar o objetivo do projeto com as diferentes expectativas dos funcionários foi, segundo a visão de alguns entrevistados da TELEMAR, sentido como uma discrepância entre o que estava por ser feito e o que estava sendo conseguido sem as motivações coniventes à situação.

Por outro lado, na COSERN o modelo administrativo que passou a se institucionalizar permitiu que novos líderes informais auxiliassem os líderes formais rumo à antecipação dos problemas que, porventura, se fizessem presentes.

A gestão participativa impactou de forma positiva a transposição, tanto dos dados que, antes de migrar para o novo sistema foram remodelados, como da forma antiga para a forma nova de executar as atividades empresariais.

Os únicos pontos em comum encontrados para os dois casos foram em relação à visão do gestor, pois para os gestores de ambas as empresas, especificamente os que se atêm às ferramentas gráficas e decisórias deste sistema, o ERP causou um bom impacto e uma grande expectativa de antever obstáculos antes que estes se transformem em pesadelos.

$\mathrm{O}$ outro aspecto era quanto ao ERP ser um sistema que atende de forma superior ao processamento de transações, pois qualquer erro no começo do processo é logo identificado e passível de correção, ao passo que, como ferramenta de gestão ele é imprescindível, mediante o grande volume de informações e o desafio de dar um sentido a elas.

Desta forma, o que se percebe nas empresas pesquisadas é que quanto mais distanciado for o setor da alta administração dos demais setores, mais chances do impacto de, seja qual for a decisão, vir sob a forma de pressão; e quanto mais estreita for a ligação e o entrosamento entre os níveis (gerencial e operacional), mais motivações e interesse as pessoas envolvidas terão em se adaptar às transformações, inclusive melhorando-as, tanto por meio da inovação como através da evolução do que já existe.

Além disso, quanto mais consistente o conhecimento obtido pela empresa, seja através do canal aberto externamente (avaliação do mercado) ou internamente (identificação das expectativas dos funcionários), mais a organização passa a conhecer-se, gerando menos incertezas, menos inseguranças e possibilitando um crescimento coerente à era em estamos, a era da informação. 
Portanto, o ideal é que as empresas elaborarem o plano estratégico de forma que este seja o ponto de partida rumo aos objetivos traçados, adaptando seus sistemas e fazendo uso de metodologias que contemplem, não somente a obtenção do lucro com custos reduzidos, como também o desenvolvimento intelectual dos recursos humanos.

A implantação de um sistema ERP, por ser um projeto empresarial e não apenas tecnológico, deve ter o respaldo na qualificação das informações, por ele processadas e disseminadas. Sem a aculturação dos funcionários perante a responsabilidade dos seus atos e o engajamento a um fim geral e comum, as informações não serão bem administradas.

\begin{abstract}
The philosophy of an Enterprise Resource Planning (ERP) causes cultural and behaviorist changes of high risk, cost and complexity. Then, the importance to analyze and to ponder on the relation cost $\mathrm{x}$ benefits. This work is the result of a study of multiple cases carried through in the TELEMAR/Natal and COSERN, being based on the referring information to the relative impacts to the implantation of system ERP. A descriptive-exploratory research was carried out through questionnaires with the managers of these companies, looking for describing the use of system ERP, exploring the inherent subjects to a project of so high cost and complexity. It concludes that the ideal is that the companies must elaborate the strategical plan, and then follow its objectives, adapting its systems and making use of methodologies that they contemplate, not only the attainment of the profit with reduced costs, but also the intellectual development of the human resources.
\end{abstract}

Key words: Enterprise Resource Planning, ERP, Impacts

\title{
Referências
}

BUCKHOUT, S.; FREY, E.; NEMEC Jr., J. Por um ERP eficaz. HSM Management, n. 16, v. 3., 1999.

KALAKOTA, R.; ROBINSON, M. E-business: estratégias para alcançar o sucesso no mundo digital. 2. ed. Porto Alegre: Bookman, 2002.

MENEZES, H. Comércio eletrônico para pequenas empresas. Santa Catarina: Visual Books, 2003.

REZENDE, D. A.; ABREU, F. Tecnologia da informação: aplicada a sistemas de informações empresariais. 2. ed. São Paulo: Atlas, 2001.

RAMOS, A. S. M.; MIRANDA, A. L. B. Processos de adoção de um sistema integrado de gestão: uma pesquisa qualitativa com gestores da Unimed/Natal. In. ENCONTRO NACIONAL DE ENGENHARIA DE PRODUÇÃO, 23. , 2003, Ouro Preto. Anais... Porto Alegre: ABEPRO, 2003.

SOUZA, C. A.; ZWICKER, R. Implementação de sistemas ERP: um estudo de casos comparados. In. ENCONTRO DA ASSOCIAÇÃO DOS PROGRAMAS DE PÓS-GRADUAÇÃO EM ADMINISTRAÇÃO, 24., 2000, Florianópolis. Anais... Rio de Janeiro: ANPAD, 2000.

TORALDO, R. S.; SAPORITI, A. F.; ZANQUETTO FILHO, H. Implementação de um sistema ERP: o caso de uma grande empresa. In. ENCONTRO NACIONAL DE ENGENHARIA DE PRODUÇÃO, 21., 2001, Salvador. Anais... Porto Alegre: ABEPRO, 2001.

WOOD JR, T.; CALDAS, M. P. The part and the whole: reductionism and complex thinking in ERP system implementation. In: ENCONTRO DA ASSOCIAÇÃO DOS PROGRAMAS DE PÓS-GRADUAÇÃO EM ADMINISTRAÇÃO, 24., 2000, Florianópolis. Anais... Rio de Janeiro: ANPAD, 2000.

YIN, R. K. Estudo de caso: planejamento e métodos. 2. ed. Porto Alegre: Bookman, 2001. 